Old Dominion University

ODU Digital Commons

Psychology Faculty Publications

Psychology

1997

\title{
Prejudice Toward Fat People: The development and Validation of the Antifat Attitudes Test
}

\author{
Robin J. Lewis \\ Thomas F. Cash \\ Old Dominion University \\ Lora Jacobi \\ Old Dominion University \\ Cristina Bubb-Lewis \\ Old Dominion University
}

Old Dominion University, rlewis@odu.edu

Follow this and additional works at: https://digitalcommons.odu.edu/psychology_fac_pubs

Part of the Clinical Psychology Commons

\section{Repository Citation}

Lewis, Robin J.; Cash, Thomas F.; Jacobi, Lora; and Bubb-Lewis, Cristina, "Prejudice Toward Fat People: The development and Validation of the Antifat Attitudes Test" (1997). Psychology Faculty Publications. 92.

https://digitalcommons.odu.edu/psychology_fac_pubs/92

\section{Original Publication Citation}

Lewis, R. J., Cash, T. F., Jacobi, L., \& BubbLewis, C. (1997). Prejudice toward fat people: The development and validation of the antifat attitudes test. Obesity Research, 5(4), 297-307. doi:10.1002/j.1550-8528.1997.tb00555.x

This Article is brought to you for free and open access by the Psychology at ODU Digital Commons. It has been accepted for inclusion in Psychology Faculty Publications by an authorized administrator of ODU Digital Commons. For more information, please contact digitalcommons@odu.edu. 


\title{
Prejudice Toward Fat People: The Development and Validation of the Antifat Attitudes Test
}

\author{
Robin J. Lewis, Thomas F. Cash, Lora Jacobi, Cristina Bubb-Lewis
}

\begin{abstract}
LEWIS, ROBIN J, THOMAS F CASH, LORA JACOBI, CRISTINA BUBB-LEWIS. Prejudice toward fat people: The development and validation of the Antifat Attitudes Test. Obes Res. 1997;5:297-307.

Although the stigma of obesity in our society is well documented, the measurement of antifat attitudes has been a difficult undertaking. Two studies were conducted to construct and validate the Antifat Attitudes Test (AFAT). In study 1, college students (110 men and 175 women) completed the preliminary 54-item AFAT and specific indices of body image and weight-related concerns. Psychometric and factor analysis revealed a 47-item composite scale and three internally consistent factors that were uncorrelated with social desirability: Social/Character Disparagement, Physical/Romantic Unattractiveness, and Weight Control/Blame. Several body image correlates of antifat prejudice were identified, and men expressed more negative attitudes than women. Study 2 experimentally examined the effects of information about the controllability of weight on the antifat attitudes of 120 participants. Exposure to information on behavioral vs. biogenetic control led to greater blame of persons who are fat for their body size. The implications of the findings and the potential utility of the AFAT are discussed.
\end{abstract}

Key words: antifat attitudes, stereotyping, fat prejudice, fat acceptance

\section{Introduction}

In social discourse in America, disparaging remarks about people who are "fat," "overweight," or "obese" are

Submitted for publication May 9, 1995.

Accepted for publication January 15, 1997

From the Department of Psychology, Old Dominion University, Norfolk, VA.

Reprint requests for the Anti-fat Attitudes Test should be addressed to either Robin J.

Lewis or Thomas F. Cash, Department of Psychology, Old Dominion University,

Norfolk, VA 23529-0267.

Copyright 10 1997 NAASO. not unusual. Such offhand comments are often met with laughter or agreement. Obesity undoubtedly carries a social stigma. In 1990, for example, an article appeared in the "My Turn" section of Newsweek magazine warning "fatties" not to tell themselves "you don't look so bad, [because] you do" (26). This commentary illustrates the existence of a socially acceptable prejudice toward fat people. ${ }^{1}$

Substantial research affirms that stereotypes of endomorphy are prevalent across the lifespan and are generally unfavorable $(8,19)$. Through social modeling by parents, peers, and the media, children acquire antifat attitudes at an early age $(20,37)$. People ascribe many undesirable attributes to individuals who are fat, merely by observing their physical size $(23,35)$. A recent "free-response" study of physique stereotypes (6) found that endomorphs are characteristically viewed as social rejects, slobs, and clowns.

A variety of measures have been developed to assess antifat attitudes (see ref. 42, for a review). These measures were generated from a variety of theoretical perspectives and for different purposes. Some measures tapped global attitudes that were both self-relevant (e.g., personal fears of fatness) and other-relevant. Others focused more on social attitudes about persons who are overweight or obese. In addition, few measures have been used in more than one or two studies, which raises questions about generalizability. Further, many of the early measures lacked information on reliability and validity. Thus, the purpose of this study is to report the development and initial validation of a measure of antifat attitudes. The sound measurement of antifat attitudes is crucial in researchers' attempts to understand better the prejudice and discrimination against people who are fat in our society. As Yuker et al. (42) point out, negative attitudes about persons who are obese are frequently held by both health professionals and laypersons. Furthermore, beliefs

\footnotetext{
${ }^{1}$ As Crandall (15) has also explained, we use the terms fat and antifat descriptively and not pejoratively, reflecting their preferability in accordance with the official position of the National Association to Advance Fat Acceptance, in addition to words with medical or normative connotations such as obese or overweight.
} 
about the causes of obesity seem to be related to attitudes toward individuals with obesity. By enhancing our knowledge of this phenomenon, we can be more successful in our efforts to combat it.

Allison et al. (2) developed measures to assess attitudes and beliefs about persons who are obese. These investigators used three samples-members of the National Association to Advance Fat Acceptance (NAAFA), graduate students, and undergraduates. Thus, this varied sample consisted of individuals who presumably had positive attitudes toward people who are fat as well as student samples who were assumed to have neutral to negative attitudes. Analyses yielded the following three factors: I. "Different Personality" reflecting the attribution of different or negative personality characteristics to people who are fat; II. "Social Difficulties" related to the perception that persons with obesity have social problems; and III. "Self-Esteem," which concerns how people who are fat perceive themselves. Unfortunately, by including individuals belonging to NAAFA, many items also became self-relevant, as reflected on the third factor, Self-Esteem. Therefore, it is unclear whether the scale is measuring attitudes toward others or acceptance of self. Of interest, however, is their finding that belief about the controllability of weight was consistently related to attitudes. People who believed that obesity is largely beyond one's control had more positive attitudes toward individuals with obesity. Gender was also related to attitudes, with men having more positive attitudes. Women tended to have their perceptions influenced by their own weight, although the details of this finding are not specified.

Robinson et al. (32) recently developed the Fat Phobia Scale, defining "fat phobia"' as a pathological fear of fatness. Their 50-item measure included a number of characteristics that might be seen to apply to people who are fat, such as lazy vs. industrious and good vs. bad. Items were developed by asking individuals in the general population to list descriptors of people who are fat. All subsequent research, however, involved participants who were hearing talks on body image, who were beginning a treatment program for body image/fat phobia, or who had read an article on these topics. Thus, their sample of participants was clearly biased in the direction of including those who were concerned about weight and body image. Although the scale has adequate internal consistency, its convergent and discriminant validity is unknown. Factor analysis yielded six factors: (1) Undisciplined/Inactive/Unappealing; (2) Grouchy/Unfriendly; (3) Poor Hygiene; (4) Passivity; (5) Emotional/Psychological Problems; and (6) Stupid/ Uncreative. Fat phobia was related to several demographic variables. Reports of greater fat phobia tended to occur among individuals who had lower body mass indices (BMIs), were younger, were women, had more than a high school education, and were nonmedical professionals.

Crandall and Biernat (17) also developed a self-report inventory to measure antifat attitudes. Unfortunately, some of the item content is confounded by social desirability, perceived health risks, assumed stigma, or personal weight anxiety. For example, one item is "I would like my child to be ... of normal weight." Endorsement of this item may indeed reveal an antifat attitude, such as "I don't like fat people, and therefore I would not want my child to be fat." However, it may also reflect an assumption of obesity's health risks or a recognition of the social stigmatization of fat people. After all, who would wish one's child to be unhealthy or be socially ridiculed and rejected? Other similarly problematic items are "One of the worst things that could happen to me would be if I gained 25 pounds" and "Being fat is one of the worst things a person can do to his or her health." Surely, one can hold these beliefs without necessarily having disparaging, stereotypic attitudes about people who are fat. Finally, Crandall and Biernat's Antifat Attitudes Scale consists of only five items, most of which pertain to feelings about becoming fat. Thus, it does not adequately sample the various facets of interpersonal attitudes, namely, cognitive, affective, and behavioral dispositions toward people who are fat. Despite its narrow focus, the scale has marginal internal consistency (i.e., a Cronbach's $\alpha$ coefficient of 0.65 ).

Crandall (16) subsequently developed the Antifat Attitudes Questionnaire, which seems to have a somewhat broader focus. Its initial 26 items sampled domains of personal relevance, willingness to interact with fat people, and cause of fatness. On the basis of a factor analysis of the scale with an undergraduate population, 13 items were retained and the following three factors were identified: Dislike, Fear of Fat, and Willpower. Dislike and Willpower were correlated with one another, but neither was correlated with Fear of Fat.

Maiman et al. (29) constructed a 22-item antifat scale but did not report validity or reliability information. Although their scale was not factor analyzed, they hypothesized three dimensions: Disparaging Image of Obese Persons, Causes of Obesity, and Ways to Lose Weight. Other recent measures that have demonstrated adequate reliability yield inconsistent results when factor analyzed (42).

As Yuker et al. (42) indicate, measures of antifat attitudes assess different aspects of these attitudes. Accordingly, comparing these measures is sometimes problematic. However, one important component seems to be the degree to which the measure assesses social attitudes per se vs. self-relevant information. There appears to be consistency, with several measures converging to yield a factor or subscale related to a negative view of people who are fat. Beyond that, the measures appear to vary in terms of whether they assess perceptions of others or one's own fears of becoming fat. The two constructs-(a) self-referential fat anxiety/concern and (b) social attitudes toward persons who are fat-are conceptually distinct and should be distinc- 
tively operationalized and measured. Researchers can then more clearly evaluate a hypothesized empirical relationship (16) between personal fat anxiety and antifat social prejudice.

The salience of prejudice against people who are fat in our society and the limitations of extant measures of this prejudice prompted our development of a conceptually and psychometrically acceptable self-report inventory of antifat attitudes. Two studies were conducted. In the first study, we constructed the Antifat Attitudes Test and evaluated its reliability, its factor structure, and its discriminant and convergent validity. The study examined whether stronger antifat attitudes would be espoused by persons apprehensive about being or becoming fat and by persons motivated to achieve the physical antitheses of fatness stereotypes, namely, physical attractiveness and fitness/health. We also examined gender differences in antifat social attitudes, which remains an unresolved question (27).

The second, experimental investigation examined whether exposing people to factual information about the biogenetic causes of obesity vs. information on behavioral strategies for weight control would influence antifat attitudes. Harris et al. (24) presented college students with factual information about obesity in the context of an interview with an expert on obesity. Students' knowledge and attitudes about obesity were then assessed. Attitudes were measured by asking participants to rate "most substantially overweight women" on 18 adjectives. These researchers found that although participants' factual knowledge about obesity did increase, greater knowledge was not associated with attitude change. However, it is unclear from the authors' description precisely what factual information about "the causes and treatment of obesity" was provided to their participants.

Crandall (16) was more successful in altering antifat attitudes. Beliefs about willpower and dislike of people who are fat were altered favorably after exposure to information about the causes of obesity. Crandall concluded that, "When participants are persuaded that fat people are not responsible for their condition, they become more accepting of fat people"' (p. 888). This conclusion is consistent with findings based on social attribution theories. Weiner (40) reviewed evidence indicating that more negative attitudes are directed toward stigmatized persons when they are perceived to be responsible for their behavior/condition (i.e., when it is uncontrollable) than when they are seen as not responsible (i.e., due to an uncontrollable cause). For example, DeJong (18) found that participants' attribution of obesity to a medical condition lessened its social stigma. Therefore, we hypothesized that participants would have stronger antifat attitudes after exposure to information on the behavioral controllability of weight than after exposure to evidence substantiating its significant biogenetic control.

\section{Method}

\section{Study 1}

Participants. Among students at Old Dominion University, 110 men and 175 women served as anonymous participants in exchange for extra class credit. Their ages ranged from 18 to 49 years $(M=22.3, S D=5.5)$. A $76 \%$ majority were white, $17 \%$ were African-American, and $7 \%$ were from other minority groups. Participants completed the following questionnaires and procedures.

Measures. The initial version of the AFAT consisted of 54 statements about "fat people." A nine-member research team generated these items to reflect antifat attitudes without any of the aforementioned confounding of content. We specifically attempted to exclude items in which negative attitudes about people being fat could actually reflect concerns about health risks associated with obesity or empathic concerns that persons with obesity might be victims of societal prejudice. $^{2}$ No items pertained to respondents' judgments or feelings about their own body size or weight. Items sampled cognitive, affective, and behavioral dispositions toward people who are fat, including personal emotional reactions to people who are fat and beliefs about their personality, physical and interpersonal attractiveness, eating behaviors, weight determinants, and societal rights. Participants used a 5-point Likert-type scale ranging from strongly disagree (1) to strongly agree (5) to indicate their extent of endorsement of each item. Item wording included statements that were indicative as well as contraindicative of antifat attitudes.

The Goldfarb Fear of Fat Scale (GFFS) is a 10-item scale to assess personal fears of weight gain and becoming fat on a 4-point response format (21). The GFFS has high test-retest reliability $(r=0.88)$, good internal consistency $(\alpha=0.85)$, and validity in differentiating bulimics, repeat dieters, and dieters.

The 69-item Multidimensional Body-Self Relations Questionnaire (MBSRQ) provides a well-validated, attitudinal assessment of multiple facets of body image $(11,15)$. The subscales used in this study measured participants' cognitive-behavioral investment in three physical domainsappearance (Appearance Orientation; 12 items), competence (Fitness Orientation; 13 items), and health (Health Orientation; 8 items). A composite Fitness/Health Orienta-

\footnotetext{
${ }^{2}$ We attempted to word our items in such a way to ensure that they reflected the participants' own attitudes toward fat people rather than empathic concerns about the negative societal consequences that occur for fat people. For example, Item 7 addresses the respondent's potential shame about a family member being fat ("If someone in my family were fat, I'd be ashamed of him or her'). An alternative wording of this notion might have been, "I would not want someone in my family to be fat." This latter wording would potentially confound the respondent's own negative attitudes ("I would feel negatively toward a fat family member") with the respondent's awareness of the negative consequences to fat family member ("I would not want my family member to be fat because he or she would suffer in our society"). Thus, we attempted to word our items to reflect the respondents' own attitudes toward fat people rather than concerns based on awareness that in our society fat people are socially stigmatized and mistreated.
} 
tion subscale may be derived. Confirmed by factor analyses (4), these reliable Orientation subscales tap the importance of and attention paid to the domain, as well as behaviors for improving or maintaining the domain (9). The MBSRQ uses a 5-point, disagree-agree response format.

The in vivo Weigh-In Distress procedure assesses anxiety experienced while being weighed, without receipt of feedback about actual weight $(12,34)$. Immediately after stepping off the balance-beam scale, participants give a written rating of their subjective distress during the weighin, from "completely relaxed and comfortable" $(0)$ to "extremely tense and uncomfortable" (100). This measure has been shown to be related to self-reported satisfaction with appearance and discrepancy between perceived body size and ideal body size (28). This procedure has been reported to be sensitive to therapeutic change (7).

The Social Desirability Scale (SDS; 31 ) is a 13-item, shortened version of the original Marlowe-Crowne Social Desirability Scale. The true-false SDS measures participants' proclivity to present themselves in a socially desirable or conforming manner. High scores can also indicate a genuine need for the approval of others. This short version correlates well with the original long form $(r=0.93)$ and has good 6-week stability $(r=0.74)$.

Procedure. Participants received self-administered packets containing an informed consent form, the selfreport inventories described above, and a demographic data sheet. To minimize potential reactive or carryover effects, packets were assembled by counterbalancing the order of the scales and placing "neutral" demographic and SDS questionnaires between the AFAT, GFFS, and MBSRQ. When returning completed packets a week later, participants were weighed, the Weigh-In Distress measure was taken, and they were debriefed.

\section{Results and Discussion}

Before a factor analysis on the AFAT was performed, item-total correlations were calculated separately for men and women. Any item that failed to correlate at least 0.30 with the total score for either gender was deleted from further analysis. Among the original 54 items, 7 were eliminated for this reason.

A principal-components factor analysis with varimax rotation was conducted on the remaining 47 items. $^{3}$ The decision to extract three factors was based on inspection of a screen plot. An item was selected for inclusion on the

\footnotetext{
${ }^{3}$ We initially examined the AFAT using both varimax and oblique rotations. The oblique rotation procedure did not result in a solution after 25 iterations. Thus, initially, we chose to use the varimax procedure. When the factor analysis was redone using only the 34 items that loaded on the subscales, we used both a varimax and an oblique rotation procedure. The resultant solutions were quite similar. Furthermore, when the analyses were redone using only the subscale items, the amount of variance accounted for by each factor was similar to the original analysis. Thus, we are reporting the factor analysis for all 47 items on the AFAT using the varimax rotation.
}

subscale when its loading on the factor equaled or exceeded 0.40 . Multiply loading items were not included on any factor. Three factors were identified and accounted for $41 \%$ of the total variance. Among the 47 items, 4 did not load on any factor and 9 did not load uniquely. Thus, 34 items loaded sufficiently and uniquely on one of the three factors. Three subscale scores were generated by summing items identified for each of the three factors and dividing by the number of items on the factor. Appropriate reverse scoring was used such that higher scores reflected greater endorsement of antifat attitudes. The intercorrelations among the three subscales ranged from 0.61 to 0.68 for men and ranged from 0.60 to 0.65 for women. Table 1 presents the factor loadings that were used to classify each item for inclusion into a subscale. Table 2 summarizes the psychometric properties of each subscale and the 47-item composite AFAT scale.

The first subscale consisted of 15 items and accounted for $31.6 \%$ of the variance of the AFAT. This subscale, termed Social/Character Disparagement, includes items ascribing socially undesirable personality characteristics to and social disregard for persons who are fat. Examples of items are: "Most fat people are boring"; "I prefer not to associate with fat people"; "If bad things happen to fat people, they deserve it"; "Society should respect the rights of fat people" (reverse scored). The internal consistency of this subscale was 0.91 for men and 0.87 for women.

The second subscale contained 10 items and accounted for $5.2 \%$ of the variance. This subscale, Physical/Romantic Unattractiveness, has items reflecting perceptions that persons who are fat are homely and are unacceptable as romantic partners Exemplary items include: "Fat people are physically unattractive"; "Fat people shouldn't wear revealing clothing in public"; "It's disgusting to see fat people eating"; "If I were single, I would date a fat person' (reverse scored). Cronbach's $\alpha$ values for this subscale were 0.79 and 0.84 for men and women, respectively.

The third subscale consisted of nine items and accounted for $4.1 \%$ of the variance. This subscale, Weight Control/Blame, taps beliefs concerning whether people who are fat are responsible for their weight. Higher scores reflect beliefs that the weight of persons are fat is under their own behavioral control vs. biogenetic control. Examples of items are: "There is no excuse for being fat"; "Fat people have no will power"; "If fat people really wanted to lose weight they could"; "Fat people do not necessarily eat more than other people" (reverse scored). Internal consistencies for the third subscale were 0.77 for men and 0.85 for women.

The 47-item composite score included the 34 unique factor items as well as the 13 items that loaded on no factor or on multiple factors. This composite was highly internally consistent, with Cronbach's $\alpha$ values of 0.95 for each gender.

As shown in Table 2, mean comparisons of men and 
Table 1. AFAT items and factor loadings

\begin{tabular}{|c|c|}
\hline Item & Loading \\
\hline \multicolumn{2}{|l|}{ I. Social/Character Disparagement } \\
\hline $\begin{array}{l}\text { 9. If fat people don't get hired, it's their own } \\
\text { fault. }\end{array}$ & 0.46 \\
\hline $\begin{array}{l}\text { 12. Fat people don't care about anything except } \\
\text { eating. }\end{array}$ & 0.64 \\
\hline 13. I'd lose respect for a friend who started & \\
\hline getting fat. & 0.58 \\
\hline 14. Most fat people are boring. & 0.54 \\
\hline 16. Society is too tolerant of fat people. & 0.58 \\
\hline $\begin{array}{l}\text { 17. When fat people exercise, they look } \\
\text { ridiculous. }\end{array}$ & 0.44 \\
\hline $\begin{array}{l}\text { 21. Fat people are just as competent in their } \\
\text { work as anyone. }\end{array}$ & -0.60 \\
\hline 23. Being fat is sinful. & 0.46 \\
\hline 26. I prefer not to associate with fat people. & 0.53 \\
\hline $\begin{array}{l}\text { 28. Most fat people are moody and hard to get } \\
\text { along with. }\end{array}$ & 0.67 \\
\hline $\begin{array}{l}\text { 29. If bad things happen to fat people, they } \\
\text { deserve it. }\end{array}$ & 0.65 \\
\hline $\begin{array}{l}\text { 30. Most fat people don't keep their } \\
\text { surroundings neat and clean. }\end{array}$ & 0.55 \\
\hline $\begin{array}{l}\text { 31. Society should respect the rights of fat } \\
\text { people. }\end{array}$ & -0.55 \\
\hline 41. Fat people are unclean. & 0.60 \\
\hline 44. It's hard to take fat people seriously. & 0.65 \\
\hline II. Physical/Romantic Unattractiveness & \\
\hline 2. If I were single, I would date a fat person. & -0.58 \\
\hline 5. Fat people are physically unattractive. & 0.65 \\
\hline $\begin{array}{l}\text { 6. Fat people shouldn't wear revealing clothing } \\
\text { in public. }\end{array}$ & 0.44 \\
\hline $\begin{array}{l}\text { 15. I can't believe someone of average weight } \\
\text { would marry a fat person. }\end{array}$ & 0.51 \\
\hline 24. It's disgusting to see fat people eating. & 0.42 \\
\hline $\begin{array}{l}\text { 32. It's hard not to stare at fat people because } \\
\text { they are so unattractive. }\end{array}$ & 0.43 \\
\hline $\begin{array}{l}\text { 36. I would not want to continue in a romantic } \\
\text { relationship if my partner became fat. }\end{array}$ & 0.55 \\
\hline $\begin{array}{l}\text { 38. I don't understand how someone could be } \\
\text { sexually attracted to a fat person. }\end{array}$ & 0.69 \\
\hline $\begin{array}{l}\text { 40. People who are fat have as much physical } \\
\text { coordination as anyone. }\end{array}$ & -0.57 \\
\hline $\begin{array}{l}\text { 42. Fat people should be encouraged to accept } \\
\text { themselves the way they are. }\end{array}$ & -0.45 \\
\hline III. Weight Control/Blame & \\
\hline 1. There's no excuse for being fat. & 0.55 \\
\hline 4. Most fat people buy too much junk food. & 0.59 \\
\hline 19. Most fat people are lazy. & 0.52 \\
\hline
\end{tabular}

Table 1. Continued

\begin{tabular}{lr}
\hline \multicolumn{1}{c}{ Item } & Loading \\
\hline 22. If fat people really wanted to lose weight, & \\
they could. & 0.64 \\
25. Fat people have no will power. & 0.52 \\
35. The idea that genetics causes people to be & \\
fat is just an excuse. & 0.60 \\
39. If fat people knew how bad they looked, & \\
they would lose weight. & 0.53 \\
43. Most fat people will latch onto almost any & \\
excuse for being fat. & 0.47 \\
45. Fat people do not necessarily eat more than & \\
other people. & -0.44
\end{tabular}

IV. Additional Items

3. Jokes about fat people are funny.

7. If someone in my family were fat, I'd be ashamed of him or her.

NL

8. I can't stand to look at fat people.

10. Fat people are disgusting.

11. If I have the choice, I'd rather not sit next to a fat person.

18. I hate it when fat people take up more room than they should in a theater or on a bus or plane.

NL

20. Most fat people don't care about anyone but themselves.

DL

27. Fat people don't care about their appearance.

DL

33. If I owned a business, I would not hire fat people because of the way they look.

DL

34. I'd feel self-conscious being seen in public with a fat person.

DL

37. The existence of organizations to lobby for the rights of fat people in our society is a good idea.

NL

46. Fat people obviously have a character flaw, otherwise they wouldn't become fat.

DL

47. It makes me angry to hear anybody say insulting things about people because they are fat.

NL

Additional items include those items that either did not load uniquely on a factor (DL) or did not sufficiently load (NL).

women on the AFAT indicated significant differences on the composite score $(p<0.002)$ and on Social/Character Disparagement $(p<0.001)$, but not on the other subscales. Thus, the fact that men held stronger antifat attitudes than did women was particularly evident on Social/Character Disparagement. Men and women held similar attitudes related 
Table 2. Factor structure, reliability, and comparisons of the sexes for the AFAT

\begin{tabular}{|c|c|c|c|}
\hline AFAT scales & Men & Women & F ratio \\
\hline \multicolumn{4}{|c|}{ I. Social/Character Disparagement (15 items) } \\
\hline $\mathbf{M}$ & 2.02 & 1.73 & \multirow[t]{3}{*}{$16.79^{*}$} \\
\hline $\mathrm{SD}$ & 0.66 & 0.53 & \\
\hline Cronbach's $\alpha$ & 0.91 & 0.87 & \\
\hline \multicolumn{4}{|c|}{ II. Physical/Romantic Unattractiveness (10 items) } \\
\hline $\mathbf{M}$ & 3.04 & 2.92 & \multirow[t]{3}{*}{2.18} \\
\hline $\mathrm{SD}$ & 0.62 & 0.70 & \\
\hline Cronbach's $\alpha$ & 0.79 & 0.84 & \\
\hline \multicolumn{4}{|c|}{ III. Weight Control/Blame (9 items) } \\
\hline M & 2.77 & 2.69 & \multirow[t]{3}{*}{$<1$} \\
\hline SD & 0.63 & 0.75 & \\
\hline Cronbach's $\alpha$ & 0.77 & 0.85 & \\
\hline \multicolumn{4}{|l|}{ Composite AFAT score (47 items) } \\
\hline M & 2.49 & 2.27 & \multirow[t]{3}{*}{$9.97 \dagger$} \\
\hline SD & 0.57 & 0.55 & \\
\hline Cronbach's $\alpha$ & 0.95 & 0.95 & \\
\hline
\end{tabular}

to Physical/Romantic Unattractiveness and Weight Control/ Blame. $^{4}$

The Pearson $r$ values for the AFAT subscale and composite scores with social desirability, calculated separately for men and women, ranged from -0.02 to +0.19 . This provides evidence of the discriminant validity of the AFAT, in that it was not simply reflecting concerns about selfpresentation.

Table 3 summarizes correlations between the AFAT scores of the participants and selected personality and physical attributes. Separate $r$ values are given for participants of each gender. Because of the number of correlations computed with a moderately large sample size, the significance level was set at $p<0.01$ to reduce testwise error.

Among the MBSRQ subscales assessing cognitivebehavioral body image investments, only one correlation with the AFAT reached significance. On the Fitness/Health Orientation subscale, men who were more invested in health and fitness espoused stronger attitudes on Weight Control/ Blame, blaming people who are fat for their weight $(p<0.005)$. Two measures, the GFFS and in vivo Weigh-In Distress, reflected the weight-related concerns of the par-

\footnotetext{
${ }^{4}$ We also analyzed the data using a 2 (gender) $\times 2$ (race) ANOVA on the three subscale scores. There were no significant main effects or interactions. There was a trend $(p=0.065)$ toward minority individuals endorsing fewer antifat attitudes compared with whites on the Physical/Romantic Attractiveness subscale $(M$ values $=2.77 \mathrm{vx}$. 2.99).
}

ticipants. Among men, the latter correlated significantly and positively with AFAT subscales Social/Character Disparagement and Weight Control/Blame and with the composite AFAT score. On the GFFS, the fat anxiety of women was positively related to all AFAT subscales and the overall composite scale.

Finally, Table 3 presents associations between AFAT scores and the bodyweight of the participants in terms of their BMI ( $\mathrm{kg}$ weight $/ \mathrm{m}^{2}$ height). For neither gender was body mass related to antifat attitudes. Scatterplots offered no indication that antifat attitudes were curvilinearly related to body mass.

The collective results of study 1 affirm the favorable psychometric properties of the AFAT. After several unsatisfactory items were deleted, a 47-item, internally consistent inventory emerged. The Flesch-Kincaid Reading Level was 6.6 , indicating that this measure could be read by a wide audience. Factor analysis yielded three internally consistent, moderately related factors for both sexes that yield subscale scores-Social/Character Disparagement, Physical/Romantic Unattractiveness, and Weight Control/Blame. In view of the moderately strong correlations ( $r$ values in the $0.60 \mathrm{~s})$ among the three factors, the fact that factors II and III explained considerably less variance ( $4 \%$ to $5 \%$ ) than factor I $(32 \%)$ is perhaps not surprising. With regard to discriminant validity, the composite and subscale scores were acceptably free of a socially desirable response set. Correlations be- 
Table 3. Pearson correlations between individual-difference variables and AFAT scores

\begin{tabular}{|c|c|c|c|c|c|}
\hline \multirow[b]{2}{*}{$\begin{array}{c}\text { Individual-difference } \\
\text { variables }\end{array}$} & \multirow[b]{2}{*}{$\begin{array}{c}\text { Participants' } \\
\text { gender }\end{array}$} & \multicolumn{4}{|c|}{ AFAT subscales } \\
\hline & & I & II & III & $\begin{array}{c}\text { Composite } \\
\text { scale }\end{array}$ \\
\hline \multirow[t]{2}{*}{ GFFS Fear of Fat } & M & 0.19 & 0.11 & -0.04 & 0.11 \\
\hline & W & $0.24 *$ & $0.34 \dagger$ & $0.32 \dagger$ & $0.31 \dagger$ \\
\hline \multirow[t]{2}{*}{ Weigh-In Distress } & $\mathbf{M}$ & $0.33 \dagger$ & 0.23 & $0.26 \dagger$ & $0.31 \dagger$ \\
\hline & W & 0.00 & -0.01 & 0.04 & -0.04 \\
\hline \multirow[t]{2}{*}{ Appearance Orientation } & $\mathbf{M}$ & 0.06 & 0.15 & 0.10 & 0.11 \\
\hline & W & -0.06 & 0.08 & 0.06 & 0.02 \\
\hline \multirow[t]{2}{*}{ Fitness/Health Orientation } & $\mathbf{M}$ & 0.12 & 0.13 & $0.30 \dagger$ & 0.16 \\
\hline & W & 0.07 & -0.01 & 0.14 & 0.06 \\
\hline \multirow[t]{2}{*}{ BMI } & M & 0.04 & -0.09 & -0.15 & -0.08 \\
\hline & W & -0.02 & -0.16 & -0.07 & -0.11 \\
\hline $\begin{array}{l}\text { Subscale I is Social/Character } \\
\text { Subscale III is Weight Contro } \\
{ }^{*} p<0.01 \text {. } \\
\dagger p<0.001 \text {. }\end{array}$ & $\begin{array}{l}\text { yement. Subscale } \\
\text { The composite A }\end{array}$ & $\begin{array}{l}\text { ical/Roma } \\
\text { ased on th }\end{array}$ & $\begin{array}{l}\text { tractivene } \\
\text { mean. }\end{array}$ & & \\
\hline
\end{tabular}

tween the AFAT and scales assessing the psychological dispositions of participants concerning their own physical attributes revealed several significant associations. More prejudicial attitudes about people who are fat were held by women who were fearful of gaining weight or becoming fat and by men who were more anxious during a weigh-in. Men with greater investments in their fitness and health were more blaming of persons who are fat holding them more responsible for their weight. Although these associations were modest in magnitude, with shared variation of $6 \%$ to $12 \%$, they do confirm that prejudice toward persons who are fat is related to body image attitudes. Unrelated to prejudice toward fatness, however, was the actual bodyweight of the participants-an interesting finding also reported by other researchers $(2,17)$.

\section{Method}

\section{Study 2}

Participants. One hundred twenty undergraduate students at Old Dominion University (60 men, 60 women) served as anonymous participants in exchange for extra class credit. Participants for study 2 had not previously participated in study 1 .

Materials and Procedure. Participants of each gender were randomly assigned to experimental conditions in which they read one of three brief articles of comparable length that the researchers had constructed. In the Behavioral-Control condition, the article described strategies (i.e., self-management of eating, nutrition, and exercise) that research has shown can promote successful weight control. In the Biogenetic-Control condition, the article discussed setpoint theory and research evidence on the powerful roles of metabolic and hereditary factors in the determination of weight, without mention of dieting and weight loss. The article for the Neutral Condition pertained to research on memory skills. To minimize demand characteristics, the experiment was presented to participants as two "unrelated" pilot studies. All instructions were given via standard prerecorded audiotape. In the "first study," they were asked to read and critique an article on "an interesting topic in psychology that was written for ultimate use in the experimenter's Master's thesis." They were asked to evaluate the clarity of the article. They were informed that it was not necessary to evaluate the correctness of the information in the article because accuracy had already been verified by an expert. Participants were given 10 minutes to read one of the three articles before answering questions about its readability and its content.

After completing this "first study," participants were asked to assist on a different research project involving opinion questionnaires that a faculty member was developing. They then completed the 13-item SDS (see study 1), followed by the AFAT. Next, they answered a series of questions designed to detect any suspicions regarding a connection between the two phases of the experiment and any feelings that the article had affected any of their responses on the scales. Finally, participants were debriefed. 
Table 4. AFAT means and standard deviations for gender $\times$ experimental conditions in study 2

\begin{tabular}{|c|c|c|c|c|}
\hline \multirow[b]{2}{*}{ AFAT subscale } & \multirow[b]{2}{*}{$\begin{array}{c}\text { Participants' } \\
\text { gender }\end{array}$} & \multicolumn{3}{|c|}{ Experimental condition } \\
\hline & & $\begin{array}{c}\text { Behavioral } \\
\text { control }\end{array}$ & $\begin{array}{c}\text { Biogenetic } \\
\text { control }\end{array}$ & Neutral \\
\hline \multirow[t]{2}{*}{ Social/Character Disparagement } & M & $1.95(0.52)$ & $2.08(0.47)$ & $1.90(0.71)$ \\
\hline & $\mathrm{W}$ & $1.77(0.69)$ & $1.48(0.37)$ & $1.68(0.50)$ \\
\hline \multirow[t]{2}{*}{ Physical/Romantic Unattractiveness } & M & $3.12(0.55)$ & $3.05(0.73)$ & $2.94(0.69)$ \\
\hline & W & $2.89(0.81)$ & $2.50(0.50)$ & $2.65(0.64)$ \\
\hline \multirow[t]{2}{*}{ Weight Control/Blame } & M & $3.05(0.63)$ & $2.78(0.70)$ & $2.59(0.79)$ \\
\hline & W & $3.04(0.78)$ & $2.40(0.69)$ & $2.52(0.65)$ \\
\hline \multirow[t]{2}{*}{ Composite Scale (47 items) } & M & $2.57(0.52)$ & $2.53(0.49)$ & $2.39(0.63)$ \\
\hline & W & $2.34(0.69)$ & $1.98(0.46)$ & $2.10(0.52)$ \\
\hline
\end{tabular}

For men (M) and women (W), standard deviations are given parenthetically.

\section{Results and Discussion}

Before examination of the effects of experimental conditions on the antifat attitudes of participants, any transparency or demands of the manipulations were evaluated. In the postexperimental inquiry, only four participants across conditions reported any thoughts that the actual purpose of the study might be to determine the effects of information on their attitudes. This fact diminishes the likelihood that any condition effects are merely the result of experimental demand characteristics. ${ }^{5}$

Replicating the findings of study 1, all AFAT subscales were satisfactorily reliable across conditions, with $\alpha$ values ranging from 0.77 to 0.89 . For each AFAT subscale, a 2 (gender) $\times 3$ (condition) between-groups analysis of variance was conducted. ${ }^{6}$ Table 4 presents cell means and standard deviations for men and women. The results indicated no significant gender $\times$ condition interaction on any of the AFAT scores. Stronger antifat attitudes occurred among men than among women on the composite score $(F[1,114]=12.36, p<0.001)$, on Social/Character Disparagement $(F[1,114]=10.74, p<0.001)$, and on Physical/ Romantic Unattractiveness $(F[1,114]=8.75, p=0.004)$, but not on the Weight Control/Blame factor $(F[1,114]=1.42$, $p=0.24$ ).

An effect of experimental conditions was significant on Weight Control/Blame, $F(2,114)=5.96, p<0.003$, but not on the other two AFAT subscales or the 47-item composite scale ( $p=0.78,0.24$, and 0.17 , respectively). Thus, despite the apparent evidence in Table 4 that among women the

\footnotetext{
${ }^{5}$ Analysis of the data without these participants produced essentially identical results. ${ }^{6} \mathrm{We}$ also conducted a $2 \times 3$ analysis of covariance using the SDS as a covariate to examine the potential effects of social desirability. This analysis did not alter the results, suggesting that SDS scores do not moderate the effects of condition on attitude score.
}

Biogenetic-Control condition yielded, as predicted, the least prejudicial attitudes on all three factors, differences were reliable only on the Weight Control/Blame factor. Scheffe comparisons across sexes indicated that, relative to both the Biogenetic-Control and the Neutral conditions, the provision of information on the behavioral controllability of weight (i.e., by effective dieting, nutrition, and exercise) produced stronger convictions that people were blameworthy for being or becoming fat $(p<0.05)$. Information on personal uncontrollability (i.e., biogenetic control) of weight did not lead to less blame than was reported after exposure to neutral information. ${ }^{7}$ Interestingly, this was the case even though both sexes indicated postexperimentally (on a scale of 0 to 4) that their AFAT responses had been more affected by the Biogenetic-Control condition $(\mathrm{M}=1.2, \mathrm{SD}=1.6)$ than by either the Behavioral-Control condition $(M=0.7$, $\mathrm{SD}=1.1)$ or the Neutral condition $(\mathrm{M}=0.3, \mathrm{SD}=0.9)$ $(F[2,117]=5.38, p=0.005)$. Even so, the magnitude of these means indicates that participants believed that whatever information they received had very little effect on their reported attitudes toward people who are fat.

In sum, the results of study 2 provided some limited evidence that information regarding the controllability of bodyweight may influence antifat attitudes. Perhaps because of the widely held assumption that weight is under personal behavioral control, information that reinforces this assumption strengthens the perceived blameworthiness of people who are fat for their weight. On the other hand, brief exposure to information about the biogenetic control of

\footnotetext{
${ }^{7}$ It is noteworthy that men in the Biogenetic-Control condition reported slightly more negative attitudes compared with men in the Neutral condition. Although not statistically significant, it appears that men moved away from the direction of the persuasive influence. A similar, seemingly counterintuitive, finding was also reported by Batson (3) in his investigation of religious beliefs.
} 
weight may be insufficient to alter preconvictions and prejudices, even if the recipients of such information "think" that it has.

\section{General Discussion}

Body size is a salient determinant of "beautyism,", which refers to social stereotyping and discrimination on the basis of physical appearance (8); body size is a core aspect of people's own body image experiences $(14,27)$. Whether on social attitudes and actions or on personal body image, obesity fosters adverse consequences in our appearancepreoccupied society, particularly for women $(5,8,22,33,38)$. As a measure of the prejudicial attitudes held toward people who are fat, the newly developed AFAT possesses sound psychometric properties and offers a promising direction for the future. The AFAT assesses these antifat attitudes in a manner that is not confounded with social desirability and not contaminated by beliefs reflecting perceived health risks or avoidance of social victimization. In addition, the AFAT taps the domain of attitudes about others without introducing self-relevant concerns about one's own weight or appearance. Further, factor analysis indicated that the AFAT reliably assesses three facets of antifat attitudes, namely, beliefs and emotions that entail the Social/Character Disparagement of people who are fat, perceptions of their Physical/Romantic Unattractiveness, and attributions of Weight Control/Blame for being fat. Consistent with attributional perspectives (40) and other research (2), beliefs regarding the controllability of weight (on the Weight Control/Blame factor) were moderately associated with prejudices about the personality and appearance of people who are fat (on the other two AFAT subscales).

Both studies here indicated that men espouse more negative attitudes toward people who are fat than do women, although the magnitude of the differences was small -0.22 for the composite score and 0.29 for Social/ Character Disparagement. This contradicts the findings of other researchers $(2,17,32)$ of more negative attitudes among women. However, their scales may assess concerns about personal fatness more than social attitudes per se, and women clearly are more anxious than men about being or becoming fat $(8,13,36)$. Indeed, Allison et al. reported that women's attitudes were related to their own perception of their weight (2). Our results are more consistent with those reported by Harris et al. (25). They found that although women indicated greater personal concern about their weight, they judged overweight women less negatively than did men. If men emphasize women's appearance more than vice versa $(8,27)$ and men hold stronger antifat attitudes, this would certainly contribute to the social and economic adversities experienced by heavier women $(22,38,39)$. Our findings highlight the need for researchers to work to distinguish perceptions of self-related weight and appearance concerns from perceptions of others related to weight and appearance. In addition, it would be valuable to obtain testretest reliability on the AFAT to examine the temporal stability of these attitudes.

Results from study 1 suggest that antifat attitudes may bear a modest relationship to personal anxieties about weight and weight gain and efforts to manage one's health and fitness. These are understandable relationships from either direction of influence. Antifat attitudes may fuel a fear of gaining weight and becoming the social category that one scorns. Alternatively, one may project phobic antipathy on people who possess what one fears.

Like other researchers $(2,17,24,25)$, we found that the actual bodyweight of the participants was unrelated to their antifat attitudes. Although Robinson et al. (32) reported a positive correlation between BMI and fat phobia, their sample was clearly biased in the direction of including people with personal concerns about their weight. Even though the absence of a relationship between one's own size and one's social attitudes might seem somewhat counterintuitive, the fact that heavier persons possess such attitudes to the same extent as slimmer persons probably contributes to the negative body image experiences of persons who are fat as well as average-weight persons who think they are fat $(9,10,13)$. However, few of our participants were truly obese; $19 \%$ had an "overweight" BMI of more than 25.0 , yet only $3 \%$ exceeded the 30.0 criterion for obesity. Further research should examine the relationship between weight and the AFAT in a sample including a substantial number of persons with obesity. Although Allison et al. (2) found that there were no significant differences in antifat attitudes between their student samples and their sample of NAAFA individuals, persons who are fat more strongly endorsed the notion that obesity is not within an individual's control. It would be interesting to examine the attitudes of individuals with obesity who are more representative than a sample of individuals who belong to a group promoting acceptance of people who are fat. Also worthy of study are the attitudes of formerly overweight people (12). The "fat-bashing" writer of the aforementioned Newsweek article (26) stated that he was a former "fatty" and attributed his 128-lb weight loss to simple selfdiscipline. "Let's face it," he asserted, "the obese will latch onto almost any excuse to justify being fat" (p. 8). Like the ex-smoker phenomenon, this disparagement of the former "attributional self" ' may serve to bolster one's sense of accomplishment and to motivate one's maintenance of change.

How certain personality variables correlate with the AFAT is a question for further research. According to the review by Cash (8), particular personality dispositions moderate social reactions based on physical appearance. If people who are high self-monitors, publicly self-conscious, or sex typed in gender identity are especially reactive to 
physical attractiveness, perhaps they also hold more disparaging attitudes about persons who are fat. As Crandall $(15,16)$ proposed, social ideological dispositions (e.g., authoritarianism, dogmatism, modern racism, and beliefs in a just world and the protestant ethic) may engender antifat attitudes. Relatedly, narcissism (30) may lead to the denigration of individuals with the stigma of obesity.

Finally, the emergence of a subscale related to attitudes about the perceived physical and romantic unattractiveness of people who are fat represents a new domain that has not been reported previously. Although others have found aspects similar to our social/character disparagement and weight control/blame, we have not seen a discussion of the degree of endorsement of the attitudes about the physical and romantic attractiveness of people who are fat. This represents an interesting area for further research, particularly in view of the difficulties that persons with obesity experience in opportunities for dating and marriage (22).

The second, experimental investigation with the AFAT indicated that exposure to information emphasizing behavioral rather than biogenetic determinants of weight may augment the blame placed on people who are fat for their weight. This supports predictions from attribution theory (40). Perhaps it is not surprising that such brief exposure did not, however, significantly alter well-ingrained perceptions of the character and appearance of persons who are fat. Harris et al. (24) also found that although exposure to information about obesity increased factual knowledge, this exposure did not lead to a change in attitudes. Crandall (16) successfully changed attitudes about the causes of obesity by reading a two-page "persuasive message" to participants and then having participants read two "fact sheets" summarizing what they had heard. Perhaps this "double dose" of information provided enough substance to alter attitudes. Nevertheless, the durability of these immediate changes remains to be seen. Wiese et al. (41) also successfully modified the attitudes of medical students using video, audio, and written components. Attitudes remained changed at a 1-year follow-up. Thus, the effect of more extensive interventions, including intensive educational and "consciousness raising" efforts, warrants future study. As Harris et al. (24) also suggest, more powerful procedures may be necessary to change such a pervasive and socially acceptable prejudice. In addition, it is difficult to know about attitude change in the absence of baseline attitudes. Future researchers may want to obtain attitudes before the presentation of information to get a clearer picture of change.

Certainly we must acknowledge the limitations of our sample as well as the relatively modest magnitude of our findings. We used an undergraduate sample, and the results of our findings need to be replicated with other samples. In addition, although we obtained significant effects, often the effect sizes were modest. Nonetheless, it is important to continue research investigating the negative attitudes held by individuals toward people who are fat. These attitudes are widespread in our society. As we increase our understanding of this phenomenon, perhaps we can be more successful in our efforts to combat it. To these ends, the AFAT is a potentially useful tool.

\section{References}

1. Adams GR, Hicken M, Salehi M. Socialization of the physical attractiveness stereotype: Parental expectations and verbal behaviors. Int J Psychol. 1988;23:137-149.

2. Allison DB, Basile VC, Yuker HE. The measurement of attitudes toward and beliefs about obese persons. Int J Eating Disord. 1991;10:599-607.

3. Batson CD. Rational processing or rationalization? The effect of disconfirming information on a stated religious belief. $J$ Pers. Soc Psychol. 1975;32:176-184.

4. Brown TA, Cash TF, Mikulka PJ. Attitudinal body-image assessment: Factor analysis of the Body-Self Relations Questionnaire. J Pers Assess. 1990;55:135-144.

5. Brownell KD. Dieting and the search for the perfect body: Where physiology and culture collide. Behav Ther. 1991;22: $1-12$.

6. Butler JC, Ryckman RM, Thornton B, Bouchard RL. Assessment of the full content of physique stereotypes with a free-response format. $J$ Soc Psychol. 1993;133:147-162.

7. Butters JW, Cash TF. Cognitive-behavioral treatment of women's body-image dissatisfaction. J Consult Clin Psychol, 1987;55:889-897.

8. Cash TF. The psychology of physical appearance: Aesthetics, attributes, and images. In: Cash TF, Pruzinsky T, eds. Body Images: Development, Deviance, and Change. New York: Guilford; 1990; pp. 51-79.

9. Cash TF. Body images and body weight: What is there to gain or lose? Weight Control Dig. 1992;2:169 ff.

10. Cash TF. Body-image attitudes among obese enrollees in a commercial weight-loss program. Perceptual Motor Skills. 1993;77:1099-1 103.

11. Cash TF. The Multidimensional Body-Self Questionnaire Users' Manual. Available from the author, Old Dominion University, Norfolk, VA, 1994.

12. Cash TF, Counts B, Huffine CE. Current and vestigial effects of overweight among women: Fear of fat, attitudinal body image, and eating behaviors. J Psychopathol Behav Assess. 1990;12:157-167.

13. Cash TF, Hicks KL. Being fat versus thinking fat: Relationships with body image, eating behaviors, and well-being. $\mathrm{Cog}$ nitive Ther Res. 1990;14:327-341.

14. Cash TF, Pruzinsky T, eds. Body Images: Development, Deviance, and Change. New York: Guilford Press; 1990.

15. Cash TF, Winstead BW, Janda LH. The great American shape-up: Body image survey report. Psychol Today. 1986; 20:30-37.

16. Crandall CS. Prejudice against fat people: Ideology and selfinterest. J Personality Soc Psychol. 1994;66:882-894.

17. Crandall C, Biernat M. The ideology of anti-fat attitudes. $J$ Appl Soc Psychol. 1990;20:227-243. 
18. DeJong $\mathbf{W}$. The stigma of obesity: The consequences of naive assumptions concerning the causes of physical deviance. $J$ Health Soc Behav. 1980;81:75-87.

19. DeJong W, Kleck R. The social psychological effects of overweight. In: Herman CP, Zanna MP, Higgins ET, eds. Physical Appearance, Stigma, and Social Behavior: The Ontario Symposium, Vol. 3. Hillsdale, NJ: Erlbaum; 1986;65-87.

20. Fabrey WJ. The media and the movement: The challenge for size acceptance. Nat Assoc Adv Fat Accept Newslett. 1993/ 1994;24:4, 7.

21. Goldfarb LA, Dykens EM, Gerrard M. Goldfarb Fear of Fat Scale. J Pers Assess. 1985;49:329-332.

22. Gortmaker SL, Must A, Perrin JM, Sobol AM, Dietz WH. Social and economic consequences of overweight in adolescence and young adulthood. $N$ Engl J Med. 1993;329: 1008-1012.

23. Harris MB, Harris RJ, Bochner S. Fat, four-eyed, and female: Stereotypes of obesity, glasses, and gender. J Appl Soc Psychol. 1982;12:503-516.

24. Harris MB, Walters LC, Waschull S. Altering attitudes and knowledge about obesity. J Soc Psychol. 1991a;13:881-884.

25. Harris MB, Walters LC, Waschull S. Gender and ethnic differences in obesity-related behaviors and attitudes in a college sample. J Appl Soc Psychol. 1991b;21:1545-1566.

26. Hecht K. Oh, come on fatties! Newsweek. 1990;September $3: 8$.

27. Jackson LA. Physical Appearance and Gender: Sociobiological and Sociocultural Perspectives. Albany: State University of New York Press; 1992.

28. Keeton WP, Cash TF, Brown TA. Body image or body images?: Comparative multidimensional assessment among college students. J Pers Assess. 1990;54:213-230.

29. Maiman LA, Wang VL, Becker MH, Finlay J, Simonson M. Attitudes toward obesity and the obese among professionals. J Am Diet Assoc. 1979;74:331-336.

30. Phares EJ, Erskine N. The measurement of selfism. Educ Psychol Measurement. 1984;44:597-608.

31. Reynolds WM. Development of reliable and valid short forms of the Marlowe-Crowne Social Desirability Scale. J Clin Psychol. 1982;38:119-125.

32. Robinson BE, Bacon JG, O'Reilly J. Fat phobia: Measuring, understanding, and changing anti-fat attitudes. Int $J$ Eating Disord. 1993;14:467-480.

33. Rodin J, Silberstein LR, Striegel-Moore RH. Women and weight: A normative discontent. In Sonderegger TB, ed. $\mathrm{Ne}$ braska Symposium on Motivation: Psychology and Gender. Lincoln: University of Nebraska Press; 1985;267-307.

34. Rucker CE, Cash TF. Body images, body-size perceptions, and eating behaviors among African-American and White college women. Int J Eating Disord. 1992;12:291-300.

35. Ryckman RM, Robbins MA, Kaczor LA, Gold JA. Male and female raters' stereotyping of male and female physiques. Pers Soc Psychol Bull. 1989;15:244-251.

36. Silberstein LR, Striegel-Moore RH, Timko C, Rodin J. Behavioral and psychological implications of body dissatisfaction: Do men and women differ? Sex Roles. 1988;19: 493-500.

37. Stager P, Burke P. A re-examination of body build stereotypes. J Res Pers. 1982;16:435-446.

38. Stake J, Lauer ML. The consequences of being overweight: A controlled study of gender differences. Sex Roles. 1987;17: $31-47$.

39. Tiggemann M, Rothblum ED. Gender differences in social consequences of perceived overweight in the United States and Australia. Sex Roles. 1988;18:75-86.

40. Weiner B. On sin versus sickness: A theory of perceived responsibility and social motivation. Am Psychol. 1993;48: 957-965.

41. Wiese HJC, Wilson JF, Jones RA, Neises M. Obesity stigma reduction in medical students. Int J Obes. 1992;16:859-868.

42. Yuker HE, Allison DB, Faith MS. Methods for measuring attitudes and beliefs about obese people. In: Allison DB, ed. Handbook of Assessment Methods for Eating Behaviors and Weight-Related Problems: Measures, Theory, and Research. Thousand Oaks, CA: Sage Publications; 1995,81-118. 